\title{
Genome sequencing and identification of cellulase genes in Bacillus paralicheniformis strains from the Red Sea
}

\author{
Siham Fatani ${ }^{1 \dagger}$, Yoshimoto Saito $^{1,2+}$, Mohammed Alarawi ${ }^{1}$, Takashi Gojobori ${ }^{{ }^{*}}$ and Katsuhiko Mineta ${ }^{1 *}$
}

\begin{abstract}
Background: Cellulolytic microorganisms are considered a key player in the degradation of plant biomass in various environments. These microorganisms can be isolated from various environments, such as soils, the insect gut, the mammalian rumen and oceans. The Red Sea exhibits a unique environment in terms of presenting a high seawater temperature, high salinity, low nutrient levels and high biodiversity. However, there is little information regarding cellulase genes in the Red Sea environment. This study aimed to examine whether the Red Sea can be a resource for the bioprospecting of microbial cellulases by isolating cellulase-producing microorganisms from the Red Sea environment and characterizing cellulase genes.

Results: Three bacterial strains were successfully isolated from the plankton fraction and the surface of seagrass. The isolated strains were identified as Bacillus paralicheniformis and showed strong cellulase activity. These results suggested that these three isolates secreted active cellulases. By whole genome sequencing, we found 10 cellulase genes from the three isolates. We compared the expression of these cellulase genes under cellulase-inducing and non-inducing conditions and found that most of the cellulase genes were generally upregulated during cellulolysis in the isolates. Our operon structure analysis also showed that cellulase genes form operons with genes involved in various kinds of cellular reactions, such as protein metabolism, which suggests the existence of crosstalk between cellulolysis and other metabolic pathways in the bacterial isolates. These results suggest that multiple cellulases are playing important roles in cellulolysis.

Conclusions: Our study reports the isolation and characterization of cellulase-producing bacteria from the Red Sea. Our whole-genome sequencing classified our three isolates as Bacillus paralicheniformis, and we revealed the presence of ten cellulase orthologues in each of three isolates' genomes. Our comparative expression analysis also identified that most of the cellulase genes were upregulated under the inducing conditions in general. Although cellulases have been roughly classified into three enzyme groups of beta-glucosidase, endo- $\beta-1,4-g l u c a n a s e$ and exoglucanase, these findings suggest the importance to consider microbial cellulolysis as a more complex reaction with various kinds of cellulase enzymes.
\end{abstract}

Keywords: Cellulase, The Red Sea, Bioprospecting, Cellulolysis, Operon, Whole genome sequencing, Gene expression analysis

\footnotetext{
* Correspondence: takashi.gojobori@kaust.edu.sa;

katsuhiko.mineta@kaust.edu.sa

†Siham Fatani and Yoshimoto Saito contributed equally to this work.

'Computational Bioscience Research Center (CBRC), King Abdullah University

of Science and Technology (KAUST), Thuwal, Saudi Arabia

Full list of author information is available at the end of the article
}

(C) The Author(s). 2021 Open Access This article is licensed under a Creative Commons Attribution 4.0 International License, which permits use, sharing, adaptation, distribution and reproduction in any medium or format, as long as you give appropriate credit to the original author(s) and the source, provide a link to the Creative Commons licence, and indicate if changes were made. The images or other third party material in this article are included in the article's Creative Commons licence, unless indicated otherwise in a credit line to the material. If material is not included in the article's Creative Commons licence and your intended use is not permitted by statutory regulation or exceeds the permitted use, you will need to obtain permission directly from the copyright holder. To view a copy of this licence, visit http://creativecommons.org/licenses/by/4.0/ The Creative Commons Public Domain Dedication waiver (http://creativecommons.org/publicdomain/zero/1.0/) applies to the data made available in this article, unless otherwise stated in a credit line to the data. 


\section{Background}

Cellulose, which is the major component of plant biomass, is the most abundant organic compound on Earth and a sustainable source of energy [1]. It is composed of a linear homologous polymer chain consisting of Dglucose residues, containing up to 10,000 glucose residues linked by $\beta$-1,4-glycosidic bonds [2, 3]. The efficient conversion of cellulose into its glucose monomers by microbes as a source of high-energy molecules helps to meet future energy needs and serves as an alternative source of renewable energy [4]. The biodegradation of $\beta$ 1,4-glycosidic bonds in cellulose biomass is carried out by free cellulases or a multienzyme complex referred to as the cellulosome, which can catalyze the hydrolysis of cellulose into sugars. These enzymes are produced by various microorganisms, such as bacteria and fungi [5].

Several cellulase-producing microorganisms with high cellulolytic activity have been isolated from the fungal genera Aspergillus and Trichoderma [6]. Cellulase activity has also been observed in bacterial genera including Alteromonas, Acetivibrio, Bacillus, Bacteroides, Cellulomonas, Clostridium, and Ruminococcus [7]. Bacillus species have been employed for production of cellulase [8, 9]. As represented by B. subtilis, a lot of studies regarding cellulase gene sequences, enzymatic activities, optimal condition for cellulolysis were published from Bacillus species. Cellulases from Bacillus are still now reported frequently $[10,11]$.

Cellulases are a group of three types of enzymes with different activities. The first type is endo- $\beta$-1,4-glucanase (EC 3.2.1.4), which can perform cleavage on internal bonds in the cellulose fibers. The second is exoglucanase (EC 3.2.1.91), which binds at the reducing or nonreducing ends of cellulose fibers and cleaves them to produce short disaccharides [12]. The third is $\beta$ glucosidase (EC 3.2.1.21), which hydrolyzes cellobioses to produce glucose molecules [8]. Recent studies have classified the cellulases of all three types as glycosidehydrolases (GHs). The glycoside-hydrolase is a group of hydrolases composed of a great number of enzymes. The Carbohydrate-Active Enzymes CAZy database [13] provides that the cellulases reported thus far are classified into of 16 widely ranging $\mathrm{GH}$ orthologous groups.

In contrast to the terrestrial environment, a small number of studies have been conducted to investigate cellulase-producing microorganisms in marine environments. However, the isolation and characterization of cellulases from marine bacteria are now more frequently reported [8]. Studies regarding marine cellulases have revealed characteristic of these enzymes with possible application of the enzyme and producing strains.

The Red Sea has unique marine environmental features compared to the other oceans. The Red Sea has been described as an oligotrophic environment consisting of one of the warmest and saltiest water bodies in the world, with year-round high UV radiation [14]. These characteristics are thought to have given rise to and modulated the evolution and diversity of microbial forms in the Red Sea. To our knowledge, cellulaseproducing microorganisms from the Red Sea environment remain unstudied. In particular, the diversity, abundance, and characteristics of cellulase genes or cellulolytic microorganisms are still far from fully explored.

In this study, cellulase-producing bacteria were isolated from the Red Sea environment. We also identified cellulase genes and revealed that they were expressed during cellulolysis and provided important information to understand the mechanism of microbial cellulolysis in detail.

\section{Results}

Isolation and Screening of Cellulase-Producing Microorganisms

Surface seawater samples were collected from a coastal region of the Red Sea at Thuwal in Saudi Arabia. The samples were diluted and spread on Nutrient Media (NM) plates and incubated at $30^{\circ} \mathrm{C}$ following a previously reported protocol [15]. Four hundred fifty-six colonies were isolated on NM plates and subsequently streaked on media containing Carboxymethyl cellulose (CMC) as the sole carbon source for the screening of cellulase-producing microorganisms. No isolates showed cellulase activity on the CMC medium plates (Table 1 ).

We then used the plankton fractions obtained from surface seawater as the source for the isolation of cellulase-producing microorganisms. Sixty strains were isolated on NM plates, and one isolate (PB1) formed a zone of clearance around the colonies on CMC medium plates after staining with Congo Red (Fig. 1). We also tried to isolate cellulase-producing bacteria from the surface of green seagrass. One hundred and twenty-six strains were obtained on NM plates, and two strains (SB2, SB3) showed a clear halo zone on CMC medium plates after staining (Table 1). We then characterized these three strains as cellulase-producing isolates from the Red Sea.

\section{Cellulase enzyme assay}

The measurement of cellulase activities for the three strains was in broth media that containing a strip of cellulose filter paper as the sole carbon source. The complete degradation of the filter paper was observed in all the PB1, SB2 and SB3 cultures whereas the control (i.e., the same culture conditions without the bacterial inoculate) showed very slight degradation of the filter paper (Fig. S1). The measurement of the amount of reducing sugar formed in broth media after four days of cultivation revealed that all three strains showed 
Table 1 Screening of cellulase-producing bacteria from seawater, seagrass and plankton fraction samples

\begin{tabular}{llll}
\hline Sample & Seawater & Seagrass & Plankton \\
\hline No. of picked colonies from NM plate & 456 & 126 & 60 \\
No. of clones showing cellulase activity on CMC plate & 0 & 2 & 1 \\
\hline
\end{tabular}

NM nutrient media; CMC carboxymethyl cellulose

maximum cellulase activity after $72 \mathrm{~h}$ of incubation (Fig. 2). The maximum activities were $0.75,0.59$ and 0.70 filter paper unit (FPU)/ml in the PB1, SB2 and SB3 isolates, respectively.

\section{Growth test under high salinity conditions}

We investigated whether our three isolates from the Red Sea have abilities to do cellulolysis under high salinity condition. First, we tested the growth of the isolates in NM broth under the salinity conditions ranging from $0.2 \%(34 \mathrm{mM})$ to $10 \%(1.7 \mathrm{M})$ at $24 \mathrm{~h}$ after inoculation. Although the growth of the three strains gradually retarded along with the concentration of $\mathrm{NaCl}$, the results clearly showed that $\mathrm{OD}_{600}$ of the isolates were $0.5-0.9$ at the concentration of $8 \%(1.4 \mathrm{M})$ and $0.12-0.36$ at $10 \%$ $(1.7 \mathrm{M}) \mathrm{NaCl}$ (Fig. S2a). Next, we tested the growth of the isolates on CMC broth where they are able to use CMC only as a carbon source under various salinity stress conditions at $48 \mathrm{~h}$ after inoculation. Compared with $\mathrm{NM}$ broth, the isolates showed lower $\mathrm{OD}_{600}$ values in $\mathrm{CMC}$ broth at all the $\mathrm{NaCl}$ concentrations. However, the isolates still showed the growth (around 0.1 of
$\mathrm{OD}_{600}$ ) in $\mathrm{CMC}$ broth under $8 \%$ salinity (Fig. S2b, Fig. S2c).

\section{Whole-Genome Sequencing of Bacterial Isolates}

The genome sequences of the three strains were determined using the PacBio RSII platform. The average of sequencing coverage was $186 x$. The obtained sequences were de novo assembled as a single circular chromosome in each strain, and no plasmids were detected in their genomes. The total genome sizes of PB1, SB2 and SB3 were 4,318,221, 4,318,038, and 4,317,481 bp, respectively (Table S1). We then conducted gene prediction, resulting in the prediction of 4362, 4441 and 4675 genes in the genomes of the three isolates, respectively.

\section{Multilocus Sequence Typing (MLST) Analysis}

To determine the phylogenetic positions of the three strains within genus Bacillus, we conducted MLST by using thirteen housekeeping genes amino acid sequences (adk, cсpA, recF, rpoB, spo0A, sucC, glpF, ilvD, pta, purH, pycA, rpoD, tpiA and gmk). The three bacterial strains were all included in the cluster of Bacillus

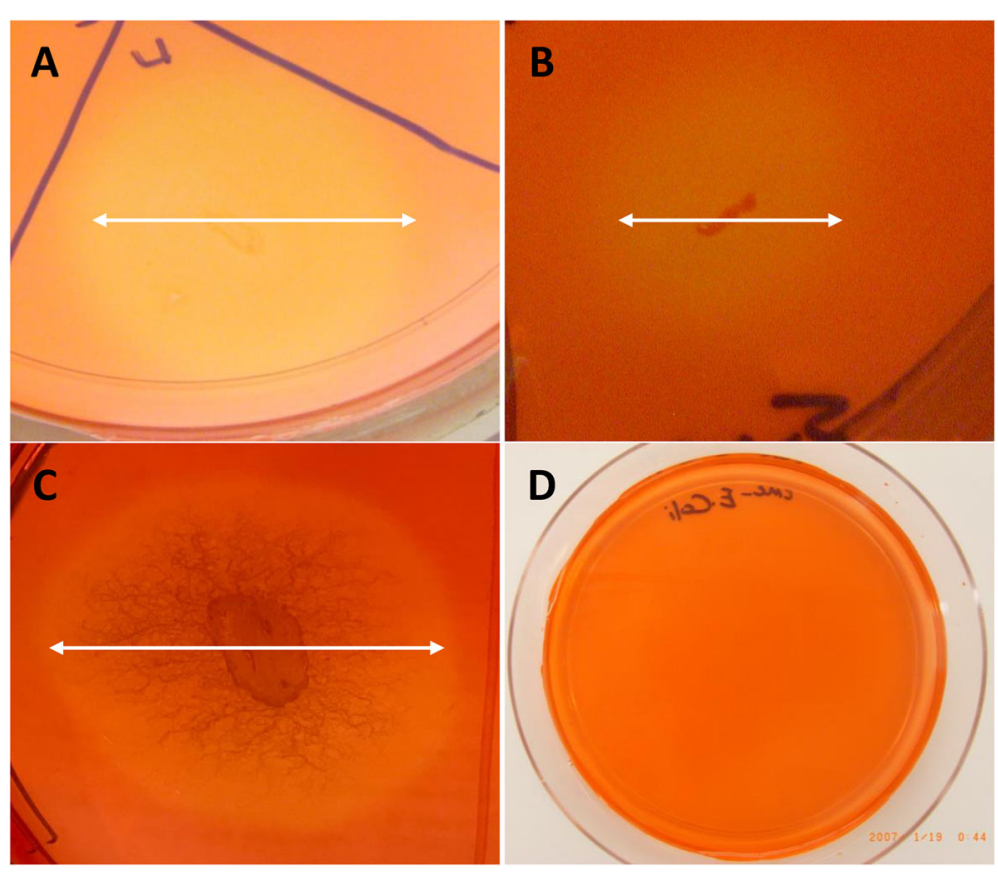

Fig. 1 Screening of cellulase-producing microorganisms by using Congo red on CMC agar plates. (A) Bacterial isolate from the plankton sample (PB1), (B and $\mathbf{C}$ ) bacterial isolates from the seagrass samples (SB2 and SB3) and (D) Escherichia coli as a negative control 


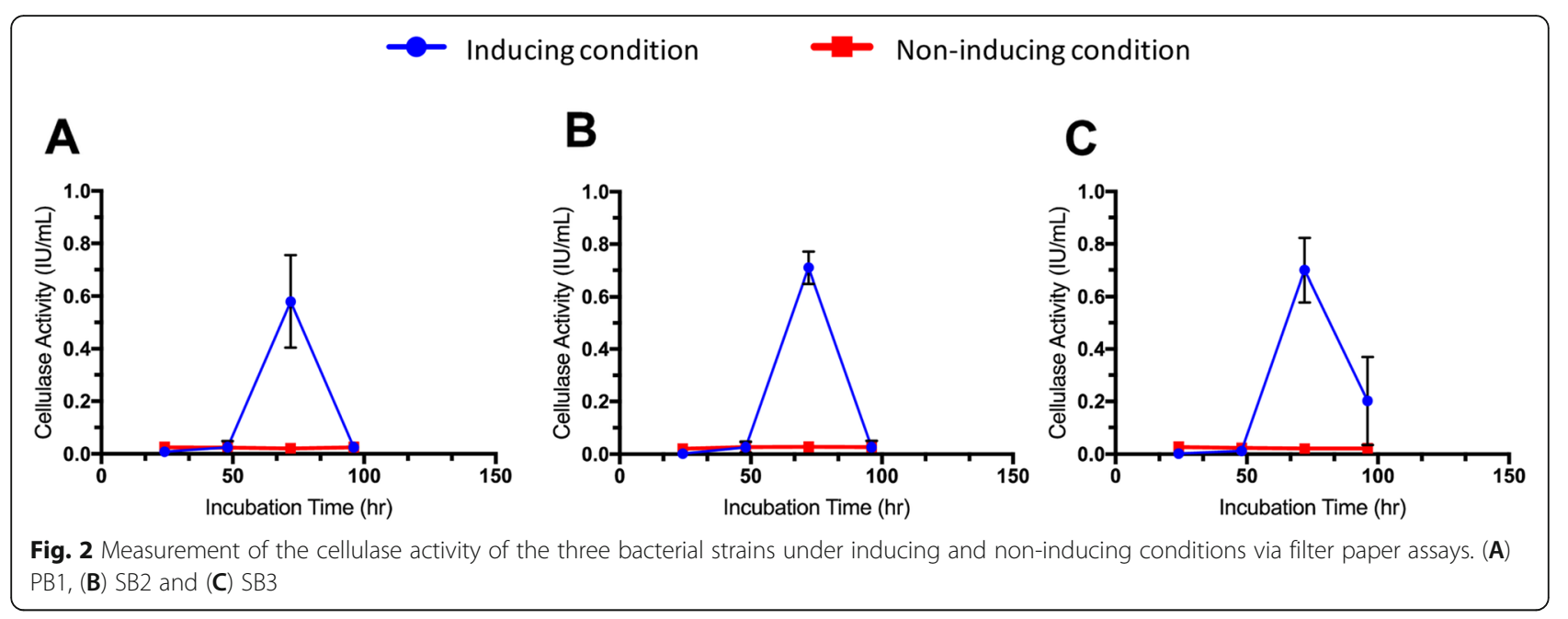

paralicheniformis strains with a $100 \%$ bootstrap value. Furthermore, the three isolates formed a cluster with $94 \%$ bootstrap support (Fig. 3).

Identification of Cellulase Genes in the Isolates' genomes We examined GH functional domains in the amino acid sequences of predicted genes and found 10, 10 and 11 cellulase genes from PB1, SB2 and SB3 strain genomes, respectively. Based on the similarity, these genes were classified into 10 orthologues and designated as Cellulase 1 to 10 (Cel-1 to Cel-10) respectively (Table 2). Amino acid sequences of each cellulase orthologue were $100 \%$ identical among three isolates. The isolates possess each orthologue as a single copy in general. Only SB3 has

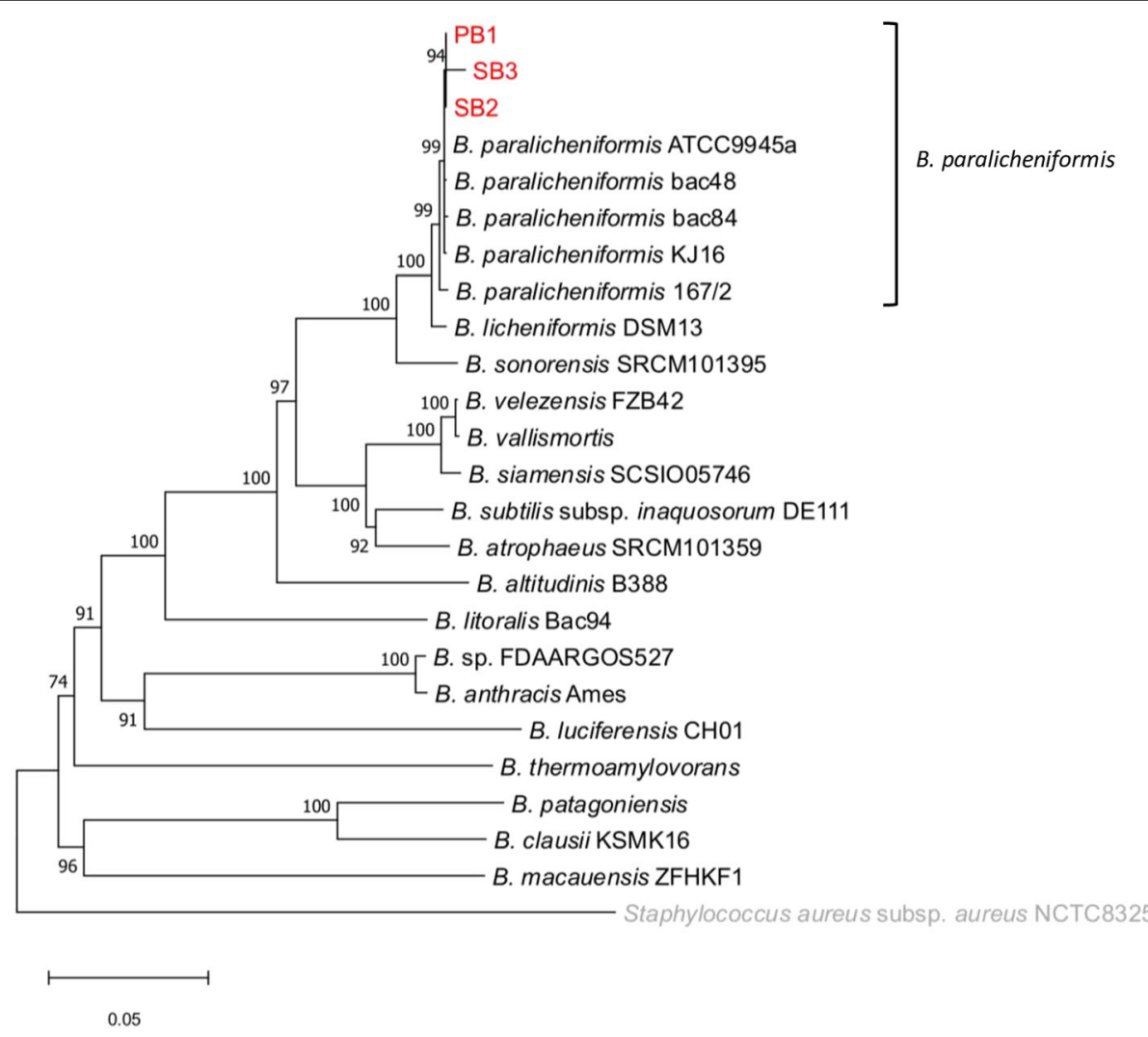

Fig. 3 Neighbor-joining phylogenetic tree based on MLST housekeeping genes in PB1, SB2 and SB3 and other Bacillus strains. The value at each node represents the bootstrap value (1,000 replicates). The units of the bar indicating the evolutionary distance are the number of nucleotide substitutions per site 
Table 2 Cellulase genes in the three isolates

\begin{tabular}{|c|c|c|c|c|c|}
\hline Cellulase orthologues & Genes in PB1 & Genes in SB2 & Genes in SB3 & GH family & Cellulase activity \\
\hline Cel-1 & GENE_769 & GENE_2609 & GENE_4396 & $\mathrm{GH} 1$ & $\beta$-glucosidase/exoglucanase \\
\hline Cel-2 & GENE_743 & GENE_2582 & GENE_4369 & $\mathrm{GH} 1$ & \\
\hline Cel-3 & GENE_1298 & GENE_3145 & GENE_288 & $\mathrm{GH} 1$ & \\
\hline Cel-4 & GENE_718 & GENE_2557 & GENE_4343 & $\mathrm{GH} 1$ & \\
\hline Cel-5 & GENE_3516 & GENE_958 & GENE_2665 & $\mathrm{GH} 1$ & \\
\hline Cel-6 & GENE_1100 & GENE_2942 & GENE_74 & $\mathrm{GH} 3$ & $\beta$-glucosidase \\
\hline Cel-7 & GENE_3008 & GENE_443 & GENE_2102 & GH5 & Endo- $\beta-1,4$-glucanase \\
\hline Cel-8 & GENE_2740 & GENE_173 & GENE_1821 & GH9 & Endo- $\beta$-1,4-glucanase/ $\beta$-glucosidase/ exoglucanase \\
\hline Cel-9 & GENE_1657 & GENE_3511 & GENE_679 & $\mathrm{GH} 26$ & Endo- $\beta$-1,4-glucanase \\
\hline Cel-10 & GENE_2741 & GENE_174 & GENE_1822 & $\mathrm{GH} 48$ & Endo- $\beta-1,4-g l u c a n a s e /$ exoglucanase \\
\hline
\end{tabular}

exceptionally two Cel-10 orthologues, GENE_1822 and GENE_1823. It is noteworthy that the amino acid sequence of GENE_1822 shows identity to the former part of Cel-10 orthologues in PB1 and SB2, while GENE_ 1823 is identical to the latter part of Ce1-10 (Fig. S3). Considering homologies to $\mathrm{GH}$ domain, orthologues of Cel-1, Cel-2, Cel-3, Cel-4 and Cel-5 were annotated as members of the GH1 family while Cel-6, Cel-7, Cel-8, Cel-9 and Cel-10 were predicted as GH3, GH5, GH9, GH26 and GH48 cellulases, respectively (Table 2).

\section{Identification of Operon Structure}

To understand what kind of genes were co-regulated with these cellulase genes, we surveyed structures of operons containing cellulase genes we found. As shown in Fig. 4, nine of the ten cellulase orthologues formed operons. We designated them as Operon-1 to Operon-8. Here, Cel-8 and Cel-10 appeared in the same operons, Operon- 8 . The structures of these eight operons were generally conserved in the three isolates.

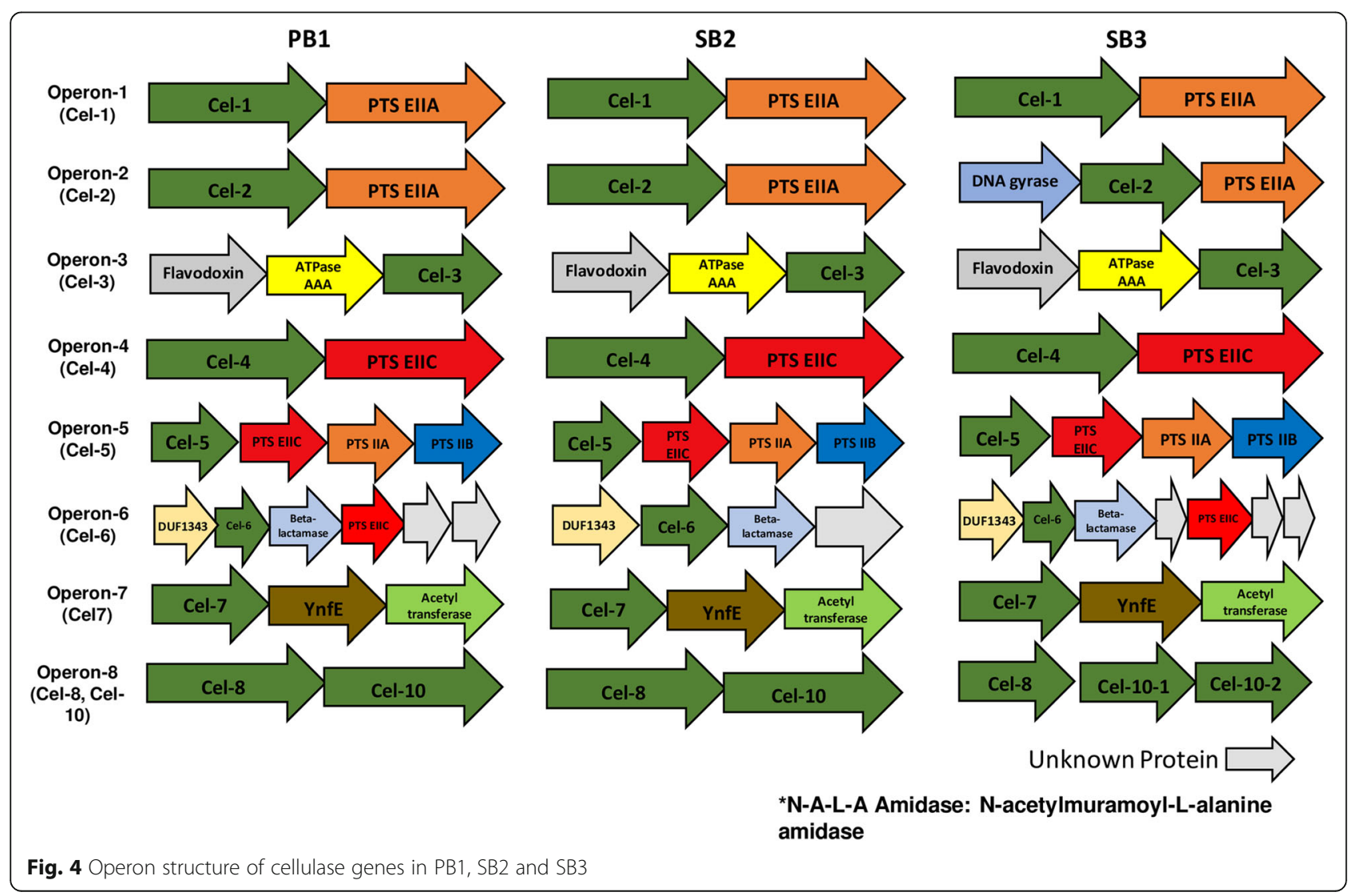


Cel-1, Cel-2 Cel-4 and Cel-5 orthologues, all of which belonged to $\mathrm{GH} 1$ cellulase ( $\beta$-glucosidase/exoglucanase), formed operons with the phosphoenolpyruvatedependent sugar phosphotransferase system (PTS) components. However, inferred functions of those PTSs were different among each operon. PTS component in the Operon-1 showed $77 \%$ identity in amino acid sequence with the PTS component of the sucrose transporting in $B$. subtilis, BglP while the sequence of the PTS component in Operon-2 was similar to the B. subtilis glucosetransporting PTS component, PtsG with $60.8 \%$ identity [16].

Operon-5 also included three PTS components with the cellulase Cel-5. These three PTS proteins showed $76 \%, 70$ and $82 \%$ sequence identities with cellobiose importing PTS components in B. subtilis, LicC (CelB), LicB (CelA) and LicA (CelC), respectively [17]. Cel-4 also formed with a PTS component in Operon-4, however, this protein did not show high homology with any known PTS components in B. subtilis. It only showed $32 \%$ amino acid sequence identities with LicC of $B$. subtilis.

On the other hand, Operon-3, which also included the GH1-type $\beta$-glucosidase Cel-3, did not contain PTS components. Genes encoding flavodoxin and AAA-type ATPase were included in this operon, instead [15].

Cel-6, another type of $\beta$-glucosidase (GH3), formed operons with two genes in Operon-6. The one encoded a protein with the conserved unknown functional domain DUF1343 (Pfam) and the other is predicted to be a $\mathrm{N}$-acetylmuramyl-L-alanine amidase gene [18].

Cel-7, which was classified as an endo- $\beta-1,4$-glucanase (GH5), formed Operon-7 with a function-unknown protein YnfE and acetyltransferase genes. The two cellulase, Cel-8 and Cel-10, which were classified as endo- $\beta-1,4-$ glucanase of GH9 and GH48 respectively, formed Operon- 8 together in all the three isolates. On the other hand, only Cel- 9 , which encoded GH26-type endo- $\beta-1,4-$ glucanase, was not included in any operons in all three isolates. It is also revealed that expression of genes included in the same operon were generally co-regulated in these three isolates (Table S2).

\section{Comparative Expression Analysis of Cellulase Genes in the Isolates}

To reveal whether the identified 10 cellulase genes are actually functional during cellulolysis, we conducted comparative expression analysis. We investigated expression of each gene under two different culture conditions: cellulase-inducing and non-inducing conditions. Enzymatic activity of cellulase was observed under cellulaseinducing conditions, i.e., after $72 \mathrm{~h}$ of incubation when it reached the maximum cellulase activity, while no cellulase activity was detected under the non-inducing conditions in all strains (Fig. 2). Because of the low number of mapped reads at PB1 (Table S3), we only focused on SB2 and SB3. The results revealed that 9 of 10 cellulase genes were upregulated in both SB2 and SB3 under the cellulase-inducing conditions (Table 3 ). In addition, each strain exhibited particular genes that were particularly highly upregulated under the cellulase-inducing conditions (i.e., showing ten-fold higher expression than under non-inducing conditions) as below.

In the SB2 strain, the expression of Cel-5 (GH1) and Cel-6 (GH3) was highly upregulated. In the SB3 strain, four genes belonging to the GH1 family, Cel-1, Cel-2, Cel-3 and Cel-4, were highly expressed or expressed specifically in the inducing condition. Cel-6 (GH3) and Cel8 (GH9) were also highly expressed in this isolate. In addition, one of the two Cel-10 (GH48) orthologues in SB3, GENE_1822 showed the expression pattern specific to the inducing condition.

\section{Discussion}

Isolation of Cellulase-Producing Microorganisms

Cellulase-producing microorganisms are usually isolated from terrestrial environments [19], whereas there are only a few reports regarding the isolation of these microorganisms from a seawater environment [20]. Harshvardhan et al. (2013) reported the isolation of the cellulolytic marine species Bacillus sp. H1666 from seawater samples along the western Indian coast [21]. Additionally, Samira et al. (2011) reported the isolation of Stenotrophomonas maltophilia from surface seawater in the Persian Gulf [22]. In our study, we could not isolate any cellulase-producing microorganisms from the surface seawater of the Red Sea. On the other hand, we report the isolation of two bacterial strains from the surface of seagrass.

This result indicates that cellulase-producing microorganisms are usually present in association with cellulosecontaining substrates such as seagrass [23], which might also explain the difficulty in isolating cellulase-producing microorganisms from shallow seawater. Previous studies supporting our results such as that of Trivedi et al. (2011) have also reported the isolation of Bacillus aquimaris, B. flexus NT and Pseudoalteromonas CSMCRI-5 strains with cellulolytic potential from green seagrass [4].

In addition, we isolated one cellulase-producing strain from the plankton fraction (i.e., samples collected from the surface seawater in which phytoplankton cells were condensed), suggesting that although the number of phytoplankton cells was very low, cellulase-producing bacteria probably live on the surface of phytoplankton cells in the Red Sea surface waters. To date, there have been no reports of the isolation of cellulase-producing microorganisms from plankton fractions; therefore, our 
Table 3 Comparative expression analysis of cellulase genes in three isolates

\begin{tabular}{|c|c|c|c|c|c|c|c|c|c|}
\hline \multirow[b]{2}{*}{ Orthologue } & \multirow[b]{2}{*}{ GH } & \multicolumn{4}{|l|}{ SB2 } & \multicolumn{4}{|l|}{ SB3 } \\
\hline & & Gene & Inducing & $\begin{array}{l}\text { Non } \\
\text { inducing }\end{array}$ & Ratio & Gene & Inducing & $\begin{array}{l}\text { Non } \\
\text { inducing }\end{array}$ & Ratio \\
\hline Cel-1 & $\mathrm{GH} 1$ & GENE_2609 & 188.18 & 81.24 & 2.32 & GENE_4396 & 3.23 & 0.18 & 18.22 \\
\hline Cel-2 & $\mathrm{GH} 1$ & GENE_2582 & 66.47 & 37.67 & 1.76 & GENE_4369 & 347.44 & 17.03 & 20.40 \\
\hline Cel-3 & $\mathrm{GH} 1$ & GENE_3145 & 15.46 & 7.49 & 2.07 & GENE_288 & 157.71 & 7.62 & 20.70 \\
\hline Cel-4 & $\mathrm{GH} 1$ & GENE_2557 & 7.90 & 2.82 & 2.80 & GENE_4343 & 19.90 & 0.00 & CMC \\
\hline Cel-5 & $\mathrm{GH} 1$ & GENE_958 & 949.03 & 2.29 & 414.79 & GENE_2665 & 21.05 & 6.57 & 3.21 \\
\hline Cel-6 & $\mathrm{GH} 3$ & GENE_2942 & 30.19 & 0.78 & 38.78 & GENE_74 & 261.19 & 0.91 & 288.46 \\
\hline Cel-7 & GH5 & GENE_443 & 48.48 & 261.73 & 0.19 & GENE_2102 & 4.23 & 2.26 & 1.87 \\
\hline Cel-8 & $\mathrm{GH} 9$ & GENE_173 & 1.23 & 0.35 & 3.48 & GENE_1821 & 43.32 & 2.08 & 20.87 \\
\hline Cel-9 & $\mathrm{GH} 26$ & GENE_3511 & 21.97 & 6.73 & 3.26 & GENE_679 & 13.55 & 7.48 & 1.81 \\
\hline Cel-10 & $\mathrm{GH} 48$ & GENE_174 & 4.51 & 0.66 & 6.87 & GENE_1822 & 16.64 & 4.61 & 3.61 \\
\hline
\end{tabular}

Values in inducing and non-inducing columns represent RPKM in each condition. Ratio columns represents ratio of RPKM values in these two conditions. "CMC" at the ratio column means the expression specific to the non-inducing condition

PB1 strain is the first isolate of a cellulase-producing microorganism associated with marine plankton.

Our growth test revealed that the three isolates are able to grow well at the concentration of $8 \% \mathrm{NaCl}$ and still slightly proliferated at $10 \% \mathrm{NaCl}$ in $\mathrm{NM}$ broth. The tolerances of the isolates against salinity are not at the same level with those of so-called halotolerant strains like B. subtilis strain FP-133 since they can grow at the concentration higher than $12.5 \% \mathrm{NaCl}$ [24]. However, Schroeter et al. reported that B. lincheniformis DSM 13 did not grow at the concentration of more than $8 \%$ $(1.4 \mathrm{M}) \mathrm{NaCl}$ [25]. Although the culturing conditions are different between Schroeter et al.'s study and ours, the isolates might be tolerant against salinity moderately. Our results also revealed that the isolates showed the growth in CMC broth at the concentration of $8 \% \mathrm{NaCl}$, which allows us to expect that the isolates can degrade the cellulose under high salinity conditions. These might be a feature of cellulase producing bacteria in the Red Sea.

Taxonomic Prediction and cellulase activity measurement B. paralicheniformis was recently described as a new species of genus Bacillus and isolated from various environments, including marine, freshwater, and foodrelated niches. In a previous study, the isolation of the bacteria $B$. paralicheniformis bac 48 and bac 84 from the Red Sea environment was reported by Othoum et al. (2018) [26]. Dass et al. (2018) isolated B. paralicheniformis F47 from a salty lake in Algeria [27]. Here, our MLST analysis showed that our three strains were closely related to $B$. paralicheniformis species. Although cellulases remain unexplored in $B$. paralicheniformis species, this species including our isolates might potentially be adaptive to high salinity environments under the hot climates such as the Red Sea. Our strains showed cellulase activities of $0.75 \mathrm{FPU} / \mathrm{ml}, 0.70 \mathrm{FPU} / \mathrm{ml}$ and $0.59 \mathrm{FPU} / \mathrm{ml}$, respectively. Although no common criteria (unit) for evaluating cellulase activity have been developed, Samira et al. (2011) measured the cellulase activities using the same method as ours except the type of the buffer (see Materials and Methods). They measured the activities of three marine bacterial isolates obtained from the Arabian/Persian Gulf and reported activities of $0.079,0.074$, and $0.072 \mathrm{FPU} / \mathrm{ml}$ for their strains. Our isolates showed more than ten times higher cellulase activity than their strains [18].

Identification of Cellulase Genes in the Isolates' genomes We also identified cellulase genes expected to be responsible for cellulolysis in each strain. Recent genome sequencing projects in cellulase-producing microorganisms have revealed the presence of several cellulase genes in their genomes [28]. The genomic analysis of our strains revealed that these three isolates possess the gene set of ten cellulase orthologues in general, and the amino acid sequences of each cellulase orthologue were identical among these three isolates. Regarding Cel-10, PB1 and SB2 have only one orthologue while SB3 has two Cel-10 orthologues. Either of Cel-10 sequences in SB3 was short and almost identical to the former or the latter part of the other isolates' Cel-10 sequences. Therefore, we should take into account the possibility of misannotation and/or sequencing errors in the genomic region including two Cel-10 orthologues in SB2, although this study conducted genome sequencing with PacBio RS II platform at 186 x coverage, allowing us to expect the high accuracy of resultant genome sequences. As far as we surveyed, this is the first report on the active cellulases in $B$. paralicheniformis. 


\section{Operon Structure Identification and Comparative} Expression Analysis of Cellulase Genes in the Isolates To determine cellulase genes expressed during cellulolysis, we conducted comparative expression analysis between two different conditions: cellulase-inducing and non-inducing conditions. Our comparative expression analysis showed that 9 of 10 cellulase genes were upregulated in SB2 and SB3 under the inducing condition. In this analysis, we omitted PB1 as the number of RNA-seq short reads mapped on open reading frame (ORF) regions in PB1 under the inducing condition was much smaller than those in the other strains (Table S3).

This study also revealed that particular types of cellulase genes were highly upregulated during cellulolysis. Most of these genes were predicted to encode $\beta$ glucosidases/exoglucanase classified as GH1 family. Our operon structure analysis identified that most of the GH1 cellulase genes formed operons with PTS system components involved in the import of various kind of sugars such as, sucrose, glucose and cellobiose [29-31]. The GH1 cellulase Cel-3 gene were also found to be included in the operon with flavodoxin and ATPases AAA protein, which is expected to be involved in diverse cellular activities [32]. Cel-6 gene, which encoded a $\beta$ glucosidase of GH3 family, were commonly included in the operon with a $\mathrm{N}$-acetylmuramyl-L-alanine amidase gene showing $63.2 \%$ identity with AmiE of B. subtilis. AmiE is revealed to be involved in the pathway of peptidoglycan recycling and in cell wall biogenesis [33]. These results suggest that these highly upregulated cellulase genes were co-regulated together with various genes present in the same operon, which enhanced a wide range of cellular reactions during cellulolysis. It is also noteworthy that the gene sets of highly upregulated GH1 $\beta$-glucosidases genes were slightly different from each other among the three orthologues, indicating that the strain-specific intracellular regulation might occur during the cellulolysis in each isolated.

On the other hand, no significant upregulation of endo- $\beta$-1,4-glucanases were observed during the cellulolysis in the expression analysis, although we confirmed the clear cellulolytic activity from the samples we used for the RNA-sEq. It may be because the expression peak of endo- $\beta-1,4$-glucanase genes had come a little bit earlier than the peak of enzymatic activity. The cellulase activity was measured by the amount of reducing sugars generated as the final product of the filter paper degradation. $\beta$-glucosidases catalyze the division of disaccharides to monosaccharides. In particular, GH3 $\beta$ glucosidases were predicted to be a secreted protein while the other $\beta$-glucosidases (i.e., GH1 proteins) were predicted to be localized inside the cell (Table S4). GH3 $\beta$-glucosidases were highly upregulated in all three isolates under the inducing condition, and the gene products were probably catalyzing the degradation of disaccharides outside the cell. High activity of GH3 $\beta$ glucosidases is consistent with the observation of the highest enzymatic activities at the same timing. More detailed time course settings may be required to characterize the expression pattern of endo- $\beta$-1,4-glucanases during microbial cellulolysis.

\section{Conclusions}

Three cellulase-producing bacteria were obtained from the plankton fraction and seagrass surface in the Red Sea environment. We identified ten cellulase genes in their genomes and revealed that those genes are expressed during cellulolysis. The Red Sea exhibits high salinity (36-40 p.s.u.) and high surface temperatures (24 ${ }^{\circ} \mathrm{C}$ in spring and up to $35{ }^{\circ} \mathrm{C}$ in summer) [14]. The isolates obtained in this study are expected to produce cellulases that may be stable under such harsh conditions. Further analysis will provide valuable information on microbial cellulases in the Red Sea, which will contribute to industrial applications such as the development of plant biomass biorefineries.

\section{Methods}

\section{Collection of Samples from the Red Sea}

Marine samples were collected from a coastal region of the Red Sea at Thuwal in Saudi Arabia on August 26 and September 30, 2015 for the isolation of cellulaseproducing microorganisms. A seawater sample was obtained from the seawater surface at the site at $22^{\circ} 17.444^{\prime} \mathrm{N}, 39^{\circ} 03.183^{\prime} \mathrm{E}$ using a Niskin bottle. A seagrass (sargassum weed) sample was obtained from the KAUST coastal marina $\left(22^{\circ} 18^{\prime} 16.7^{\prime \prime} \mathrm{N} 39^{\circ} 06^{\prime} 12.1^{\prime \prime} \mathrm{E}\right)$, and a plankton sample was collected from the sea surface by drawing a net with a mesh size of $0.63 \mu \mathrm{m}$ at $1 \mathrm{knot}$ for $10 \mathrm{~min}$. All samples were placed in sterile tubes and stored at $4{ }^{\circ} \mathrm{C}$ until use. The sample collection was followed by the institutional field research policy and procedure.

\section{Isolation and Screening of Cellulase-Producing Microorganisms}

The seawater and plankton samples were vortexed for $15 \mathrm{~min}$ in sterilized $50 \mathrm{ml}$ tubes and then allowed to settle for $5 \mathrm{~min}$. Ten-fold serial dilutions of each sample were prepared in sterilized distilled water, and $0.1 \mathrm{ml} \mathrm{di-}$ luted samples were spread on the surface of NM plates containing $0.3 \%$ beef extract, $0.5 \%$ peptone, $0.5 \% \mathrm{NaCl}$, and $1.7 \%$ agar $[\mathrm{pH} 7.0]$. The plates were incubated at $30{ }^{\circ} \mathrm{C}$ for $48 \mathrm{~h}$. One gram of seagrass was also measured and added to $10 \mathrm{ml}$ of sterilized water. One gram of glass beads $(425-600 \mu \mathrm{m})$ was placed in $1 \mathrm{M} \mathrm{HCl}$ for $1 \mathrm{~h}$ and then rinsed with distilled water. The resultant acid-washed glass beads were added to the seagrass 
tubes, which were then vortexed for $10 \mathrm{~min}$. The tubes were left for $5 \mathrm{~min}$ to allow the solids to settle, and the supernatant was collected and diluted to use it as an inoculation source and plated on NM plates [15].

To screen for cellulase-producing microorganisms, single colonies from NM were transferred to $\mathrm{CMC}$ agar composed of $0.2 \% \quad \mathrm{NaNO}_{3}, \quad 0.1 \% \mathrm{~K}_{2} \mathrm{HPO}_{4}, \quad 0.05 \%$ $\mathrm{MgSO}_{4}, 0.05 \% \mathrm{KCl}, 0.2 \% \mathrm{CMC}$ sodium salt, $0.02 \%$ peptone, and $1.7 \%$ agar. Following it, the plates were incubated at $30^{\circ} \mathrm{C}$ for $48 \mathrm{~h}$. Zones of hydrolysis were visualized by flooding the plates with $0.1 \%$ Congo red for $20 \mathrm{~min}$ and then washing the plates with $1 \mathrm{M} \mathrm{NaCl}$ for $20 \mathrm{~min}$ [15].

\section{Preparation of Extracellular Cellulase Enzymes}

The obtained cellulase-producing strains were precultured in $100 \mathrm{ml}$ of nutrient broth and incubated at $30^{\circ} \mathrm{C}$ for $48 \mathrm{~h}$ at $200 \mathrm{rpm}$. Aliquot of $2 \mathrm{ml}$ was used as the inoculum for enzyme production, and the broth culture system was composed of $0.2 \% \mathrm{NaNO}_{3}, 0.1 \% \mathrm{~K}_{2} \mathrm{HPO}_{4}$, $0.05 \% \mathrm{MgSO}_{4}, 0.05 \% \mathrm{KCl}, 0.02 \%$ peptone and a Whatman No. 1 Filter paper $(1 \times 6 \mathrm{~cm}$ strip, $0.05 \mathrm{~g}$ per $20 \mathrm{ml})$ [34]. The broth cultures were incubated for four days at $30^{\circ} \mathrm{C}$ with shaking at $200 \mathrm{rpm}$. Cell growth was monitored every $24 \mathrm{~h}$ by determining the optical density at $600 \mathrm{~nm}$, and cellulase activity was measured every $24 \mathrm{~h}$ during incubation. The cultures were centrifuged at $8,000 \mathrm{rpm}$ for $10 \mathrm{~min}$, and the supernatant was used as a source of crude enzyme for the determination of enzyme activity.

\section{Growth test under increasing salinity condition}

The growth of the three bacterial isolates under high salt condition (i.e., $0.2 \%, 2 \%, 4 \% 6 \% 8$ and $10 \%(\mathrm{w} / \mathrm{v})$ of $\mathrm{NaCl}$ ) was studied in Nutrient broth media (NM) and compared with CMC broth media (i.e., where the cellulose is a sole carbon source).

Six Nutrient broth media were prepared which composed of $(0.3 \%$ beef extract, $0.5 \%$ peptone, and $\mathrm{NaCl}$ (i.e., $0.2 \%, 2 \%, 4 \% 6 \% 8$ and $10 \%(\mathrm{w} / \mathrm{v})$ ). Likewise, for the CMC broth media, six media were prepared that contain $\left(0.2 \% \mathrm{NaNO}_{3}, 0.1 \% \mathrm{~K}_{2} \mathrm{HPO}_{4}, 0.05 \% \mathrm{MgSO}_{4}\right.$, $0.05 \% \mathrm{KCl}, 0.02 \%$ peptone, CMC $0.2 \%$ and six different concentrations of $\mathrm{NaCl}$ i.e., $(0.2 \%, 2 \%, 4 \% 6 \% 8$ and $10 \%(\mathrm{w} / \mathrm{v})$. The broth media were incubated at $30{ }^{\circ} \mathrm{C}$ with shaking at $200 \mathrm{rpm}$. Cell growth was monitored every $24 \mathrm{~h}$ up to 5 days by determining the optical density at $600 \mathrm{~nm}$.

\section{Measurement of Cellulase Activity}

The filter paper assay of Hankin and Anagnostakis was used to measure total cellulase activity in the culture [5]. Total cellulase activity was determined by measuring the amount of reducing sugar formed by the degradation of filter paper strips. Then, $0.5 \mathrm{~mL}$ of the supernatant of the culture was incubated in $1.0 \mathrm{~mL}$ of $0.05 \mathrm{M}$ sodium citrate buffer $(\mathrm{pH} 4.8)$ with a Whatman No. 1 filter paper strip, $1.0 \times 6.0 \mathrm{~cm}(=50 \mathrm{mg})$. After incubation for one hour at $50^{\circ} \mathrm{C}$, the reaction was stopped by adding 3 $\mathrm{ml}$ of dinitrosalicylic acid to the reaction mixture [35]. The amount of reducing sugars released was estimated spectrophotometrically at $540 \mathrm{~nm}$ using glucose as a standard. The enzymatic activity of total cellulases was defined in FPU/ml. One unit of cellulase activity is defined as the amount of enzyme releasing $1 \mu \mathrm{mol}$ of reducing sugars (measured as glucose) from filter paper per $\mathrm{mL}$ per $\min [34]$.

\section{Whole-Genome Sequencing}

DNA samples for the whole-genome sequencing were prepared by culturing the isolates in nutrient broth overnight at $30^{\circ} \mathrm{C}$ with shaking at $150 \mathrm{rpm}$. DNAs were extracted from the isolates using the Qiagen DNeasy Blood \& Tissue Kit following the manufacturer's instructions [36]. The obtained DNA was quantified with a Qubit dsDNA BR assay kit (Thermo Fisher Scientific). Electrophoresis was also performed in a $1 \%$ agarose gel to confirm that the length of the DNAs was longer than $40 \mathrm{~Kb}$. Fifty micrograms of DNA from each strain were used for the library construction at the Bioscience Core Lab at KAUST following the manufacturer's instruction (Pacific Biosciences) [37, 38]. The sequencing was also performed at the Bioscience Core Lab using a PacBio RS II sequencing platform (Pacific Biosciences). The largeinsert libraries were sequenced in single-molecule realtime (SMRT) sequencing cells using P6-C4 chemistry.

\section{De novo Assembly of the Genome Sequencing Data}

The row reads of each isolate generated by the PacBio RSII platform were de novo assembled and polished with HGAP3/Quiver [39]. The overlapping ends were visually checked by using Gepard v1.40, which would help indicates the circular genomes [40]. Circular closure was performed by using Minimus2 (http://amos.sourceforge. net/wiki/index.php/Minimus2) to trim the ends and permute the genome to begin at the DnaA gene (identified by BLAST), followed by Quiver-based error correction for a final closed genome. We used default parameters for Minimus2 [41].

\section{Genome Annotation}

The FGENESB_annotator was used to predict the presence of likely genes in the genomes of the bacterial isolates (http://www.softberry.com/berry.phtml?topic= fgenesb\&group=programs\&subgroup=gfindb) [42]. Recently, all known cellulases were classified based on sequence comparison into 16 glycoside-hydrolase $(\mathrm{GH})$ orthologous groups [43]. Since each GH group in the 
CAZy database is known to have a corresponding Pfam domain (Table S5) [44], the Pfam annotation was used for the identification of cellulase genes in each strain obtained in this study. The Pfam annotation of the deduced amino acid sequences of predicted genes was conducted at the Pfam-A database using the hmmscan program in HMMER (v3.0). The annotations of GH families shown in Table S5 were used to extract candidate cellulase genes, with an E-value cutoff of $<1.0 \mathrm{e}-60$ [45].

\section{Multilocus Sequence Typing (MLST) Analysis}

The phylogenetic relationships between the isolates and other Bacillus species were determined by multilocus sequence typing (MLST). The amino acid sequences of thirteen housekeeping genes from Bacillus licheniformis Table 4 (adk, ccpA, recF, rpoB and sucC) [46], Bacillus subtilis WB800N (glpF, ilvD, pta, purH, pycA, rpoD and tpiA) [47] and Bacillus anthracis CZC5 (gmk) [48] were obtained from PubMLST (http://pubmlst.org/). These thirteen genes are all the gene sets which linked to $B a$ cillus in PubMLST, except for apo0A gene which didn't find in the outgroup genome (Staphylococcus aureus subsp. aureus NCTC8325).

To perform the MLST analysis, the protein sequences of twenty-two different Bacillus species (Table S6) were obtained from the assembly database at the National Center for Biotechnology Information (https://www. ncbi.nlm.nih.gov/) and converted to the database format with the makeblastdb program of the Blast + package version 2.2.31 [49]. For three isolates obtained in this study, amino acid sequences of predicted genes were converted to the BLASTp database format. The identification of housekeeping genes for MLST analysis was conducted via BLASTp searches using thirteen housekeeping gene sequences obtained from PubMLST as a query against the protein databases of each Bacillus species. The sequences of the top-scoring hit with an Evalue lower than $1.0 \mathrm{e}-80$ and $100 \%$ query coverage were selected from the Bacillus genomes for each of thirteen genes. The selected genes were then used as query for the reciprocal Blastp search against proteomes of $B$. licheniformis DSM 13 (GenBank assembly accession: GCF_000011645.1), B. antthracis CZC5 (GCF $000534935.1)$ and $B$. subtilis WB800N $\left(\mathrm{GCF}_{-}\right.$ 003610955.1) and confirmed their orthology. The sequence alignment of each gene was conducted using MAFFT version 7.394 with default parameters, and the obtained alignments were concatenated to a single alignment manually [50]. The phylogenetic tree was constructed by the neighbor-joining method with MEGA7 [51]. Branching quality was evaluated by using a bootstrapping confidence value with 1,000 replicates [52].

\section{RNA Extraction}

The isolates were cultured under two different types of culture conditions: cellulase-inducing and non-inducing conditions. Under inducing conditions, the isolates were cultured in media composed of $0.02 \%$ peptone, $0.2 \%$ $\mathrm{K}_{2} \mathrm{HPO}_{4}, 0.05 \% \mathrm{MgSO}_{4} \cdot 7 \mathrm{H}_{2} \mathrm{O}$, and $0.2 \% \mathrm{NaNO}_{3}$ with Whatman No.1 filter paper. In the non-inducing conditions, the filter paper was excluded from the media. Cellulase activities were examined in both conditions with the method described in the Measurement of Cellulase Activity section.

Total RNA was extracted from each of these conditions after $72 \mathrm{~h}$ of incubation when it reached the maximum cellulase activity by using a QIAGEN RNeasy mini Kit (Qiagen, Valencia, CA) according to the manufacturer's protocol. Total RNA quality and concentrations were determined using the Agilent RNA 6000 Pico kit (Agilent, Santa Clara, CA) in a 2100 Bioanalyzer (Agilent). Paired-end libraries with approximate average insert lengths of 200 base pairs were synthesized using the Genomic Sample Prep kit (Illumina, San Diego, CA) according to the manufacturer's instructions. Libraries were sequenced on the Illumina HiSeq 4000 platform (Illumina, San Diego, CA) with support from the KAUST Bioscience Core laboratory [53].

\section{Expression Analysis in the Isolates}

The nucleotide sequences of ORF region of genes predicted with FGENESB program from the genome sequences were employed to build an index using the bowtie2-build program in the bowtie 2 package [54]. Only one side of the paired-end reads generated for each isolate in the RNA-seq experiments described above were aligned to the sequence index by using the Bowtie2 alignment program. The gene expression rate was determined in Reads Per Kilobase of transcript per Million mapped reads (RPKM) units with the following RPKM equation, where the number of short reads mapped onto each ORF region of predicted gene $\left(\mathrm{r}_{\mathrm{g}}\right)$ was normalized and divided by the feature length (fl.g) multiplied by the total number of mapped reads from the sequencing run (R) $[55]$ :

$$
\mathrm{RPKM}=\frac{\mathrm{r}_{\mathrm{g}} \times 10^{9}}{\mathrm{fl}_{\mathrm{g}} \times \mathrm{R}}
$$

\section{Operon Structure Identification}

The FGENESB_annotator web server was used under the default setting to predict the operon structure using the extracted genes as the input. The expression rate of the genes in the operons was determined by the same method described in the expression analysis in the isolates section. 


\section{Abbreviations}

NM: Nutrient Media; CMC: Carboxymethyl Cellulose; ORF: Open Reading Frame; RPM: Revolutions Per Minute; GH: Glycoside hydrolysis; FPU: Filter paper unit; RPKM: Reads Per Kilobase of transcript per Million mapped reads; MLST: Multilocus Sequence Typing

\section{Supplementary Information}

The online version contains supplementary material available at https://doi. org/10.1186/s12866-021-02316-w.

Additional file 1. Supplemental Materials. Description of data: Figures S1 to S3; Tables $\mathbf{S 1}$ to $\mathbf{S 6}$

\section{Acknowledgements}

We acknowledge KAUST Core laboratories of Coastal and Marine Resources and Bioscience for their support on the field sampling and sequencing.

\section{Authors' contributions}

TG, KM conceived the study; YS, KM designed the study and collected samples; SF, YS, MA conducted experiments; SF prepared the first draft with YS; TG, KM supervised research; All authors read, edited, and approved the manuscript.

\section{Funding}

The research reported in this publication was supported through funding from King Abdullah University of Science and Technology (KAUST), under award numbers BAS/1/1059-01-01, URF/1/1976-03-01, URF/1/1976-17-01, URF/1/1976-20-01 and FCS/1/3326-01-01. The funders had no role in study design, data collection and interpretation, or the decision to submit the work for publication.

\section{Availability of data and materials}

PacBio sequencing data and Illumina RNA-seq data have been deposited to the DDBJ Sequence Read Archive under accession numbers DRR228801DRR228806, and nucleotide sequences of genome assemblies and predicted genes are available in the DDBJ/ENA/GenBank nucleotide database under ac cession numbers AP023088-AP023090. PB1, SB2 and SB3 are also aliased as RSC (Red Sea Cellulase-producing bacterial strain)-1, RSC-2 and RSC-3 respectively in these databases. CAZy (http://www.cazy.org/), PubMLST (http:// pubmlst.org/), Pfam (https://pfam.xfam.org/) and NCBI (https://www.ncbi.nlm. nih.gov/) were used for obtaining reference data in this study, and these databases can be accessed openly.

\section{Declarations}

Ethics approval and consent to participate

Not applicable.

\section{Consent for publication}

Not applicable.

\section{Competing interests}

The authors declare that they have no competing interests.

\section{Author details}

${ }^{1}$ Computational Bioscience Research Center (CBRC), King Abdullah University of Science and Technology (KAUST), Thuwal, Saudi Arabia. ${ }^{2}$ Marine Open Innovation Institute (MaOI), Shizuoka, Japan.

\section{Received: 1 March 2021 Accepted: 8 September 2021}

Published online: 22 September 2021

\section{References}

1. Zverlov W, Schwarz WH. Bacterial cellulose hydrolysis in anaerobic environmental subsystems - Clostridium thermocellum and Clostridium stercorarium, thermophilic plant-fiber degraders. Ann N Y Acad Sci. 2008; 1125(1):298-307

2. Teeri $\Pi$. Crystalline cellulose degradation: new insight into the function of cellobiohydrolases. Trends Biotechnol. 1997;15(5):160-7.
3. Fukuoka A, Dhepe PL. Catalytic conversion of cellulose into sugar alcohols. Angew Chemie Int Ed Engl. 2006:45(31):5161-3.

4. Trivedi N, Gupta V, Kumar M, Kumari P, Reddy CRK, Jha B. An alkalihalotolerant cellulase from Bacillus flexus isolated from green seaweed Ulva lactuca. Carbohydr Polym. 2011;83(2):891-7.

5. Behera BC, Sethi BK, Mishra RR, Dutta SK, Thatoi HN. Microbial cellulases Diversity \& biotechnology with reference to mangrove environment: $A$ review. J Genet Eng Biotechnol. 2017;15(1):197-210.

6. Galante YM, De Conti A, Monteverdi R. Application of Trichoderma enzymes in the textile industry. Trichoderma \& Gliocladium. 2014;2:311-25.

7. Robson LM, Chambliss GH. Cellulases of bacterial origin. Enzyme Microb Technol. 1989;11(10):626-44

8. Sukharnikov LO, Cantwell BJ, Podar M, Zhulin IB. Cellulases: ambiguous nonhomologous enzymes in a genomic perspective. Trends Biotechnol. 2011:29(10):473-9.

9. $\quad$ Yang G, Yang D, Wang X, Cao W. A novel thermostable cellulase-producing Bacillus licheniformis A5 acts synergistically with Bacillus subtilis B2 to improve degradation of Chinese distillers' grains. Bioresour Technol. 2021; 325:124729.

10. Thapa S, Mishra J, Arora N, Mishra P, Li H, O'Hair J, et al. Microbial cellulolytic enzymes: diversity and biotechnology with reference to lignocellulosic biomass degradation. Rev Environ Sci Biotechnol. 2020;19(3):621-48.

11. Malik WA, Khan HM, Javed S. Bioprocess Optimization for Enhanced Production of Bacterial Cellulase and Hydrolysis of Sugarcane Bagasse. BioEnergy Res. 2021.

12. Davies G, Henrissat B. Structures and mechanisms of glycosyl hydrolases. Structure. 1995;3(9):853-9.

13. Cantarel BI, Coutinho PM, Rancurel C, Bernard T, Lombard V, Henrissat B. The Carbohydrate-Active EnZymes database (CAZy): An expert resource for glycogenomics. Nucleic Acids Res. 2009:37(SUPPL. 1):233-8.

14. Behzad H, Ibarra MA, Mineta K, Gojobori T. Metagenomic studies of the Red Sea. Gene. 2016:576(2):717-23.

15. Kasana RC, Salwan R, Dhar H, Dutt S, Gulati A. A rapid and easy method for the detection of microbial cellulases on agar plates using Gram's iodine. Curr Microbiol. 2008;57(5):503-7.

16. Deutscher J, Galinier A, Martin-verstraete I. Carbohydrate Uptake and Metabolism. In: Sonenshein AL, Hoch JA, Losick R, editors. Bacillus subtilis Its Closest Relatives: From Genes to Cells. ASM press; 2001. p. 129-50.

17. Snider J, Thibault G, Houry WA. The AAA+ superfamily of functionally diverse proteins. Genome Biol. 2008:9(4):1-8.

18. Litzinger S, Duckworth A, Nitzsche K, Risinger C, Wittmann V, Mayer C Muropeptide rescue in Bacillus subtilis involves sequential hydrolysis by $\beta$ $\mathrm{N}$-acetylglucosaminidase and N-acetylmuramyl-L-alanine amidase. J Bacteriol. 2010;192(12):3132-43.

19. Niyonzima FN. Detergent-compatible bacterial cellulases. J Basic Microbiol. 2019;59(2):134-47.

20. Lynd LR, Weimer PJ, ZyI WH Van, Pretorius IS. Microbial celullosa utilizaton: Fundamentals and Biotechnology. Bioresour Technol. 2002;66(3):506-77.

21. Harshvardhan K, Mishra A, Jha B. Purification and characterization of cellulase from a marine Bacillus sp. H1666: A potential agent for single step saccharification of seaweed biomass. J Mol Catal B Enzym. 2013:93:51-6.

22. Samira M, Mohammad R, Gholamreza G. Carboxymethyl-cellulase and filterpaperase activity of new strains isolated from Persian Gulf. Microbiol J. 2011; 1(1):8-16.

23. Joint I, Mühling M, Querellou J. Culturing marine bacteria - An essential prerequisite for biodiscovery: Minireview. Microb Biotechnol. 2010;3(5):56475.

24. Setyorini E, Kim Y, Takenaka S, Murakami S, Aoki K. Purification and characterization of a halotolerant intracellular protease from Bacillus subtilis strain FP-133. J Basic Microbiol. 2006:46(4):294-304.

25. Schroeter $R$, Hoffmann $T$, Voigt $B$, Meyer $H$, Bleisteiner $M$, Muntel J, et al. Stress responses of the industrial workhorse Bacillus licheniformis to osmotic challenges. PLoS One. 2013;8(11):e80956.

26. Othoum G, Bougouffa S, Razali R, Bokhari A, Alamoudi S, Antunes A, et al. In silico exploration of Red Sea Bacillus genomes for natural product biosynthetic gene clusters. BMC Genomics. 2018;19(1):1-11.

27. Daas MS, Rosana ARR, Acedo JZ, Douzane M, Nateche F, Kebbouche-Gana S, et al. Draft Genome Sequence of Bacillus paralicheniformis F47, Isolated from an Algerian Salty Lake. Genome Announc. 2018;6(13):4-6.

28. Feng Y, Duan C-J, Pang H, Mo X-C, Wu C-F, Yu Y, et al. Cloning and identification of novel cellulase genes from uncultured microorganisms in 
rabbit cecum and characterization of the expressed cellulases. Appl Microbiol Biotechnol. 2007;75(2):319-28.

29. Bourassa S, Vadeboncoeur C. Expression of an inducible enzyme II fructose and activation of a cryptic enzyme II glucose in glucose-grown cells of spontaneous mutants of Streptococcus salivarius lacking the low-molecularmass form of $1 I^{\text {man }}$, a component of the phosphoenolpyruvate:mannose phosphotransferase system. J Gen Microbiol. 1992;138(4):769-77.

30. Arnaud M, Vary P, Zagorec M, Klier A, Debarbouille M, Postma P, et al. Regulation of the sacPA operon of Bacillus subtilis: Identification of phosphotransferase system components involved in SacT activity. J Bacteriol. 1992;174(10):3161-70.

31. Kleerebezemab M, Hols P, Hugenholtz J. Lactic acid bacteria as a cell factory: Rerouting of carbon metabolism in Lactococcus lactis by metabolic engineering. Enzyme Microb Technol. 2000;26(9-10):840-8.

32. Sancho J. Flavodoxins: Sequence, folding, binding, function and beyond. Cell Mol Life Sci. 2006;63(7-8):855-64.

33. Zoll S, Pätzold B, Schlag M, Götz F, Kalbacher H, Stehle T. Structural basis of cell wall cleavage by a staphylococcal autolysin. PLoS Pathog. 2010;6(3): e1000807.

34. Gupta P, Samant K, Sahu A. Isolation of cellulose-degrading bacteria and determination of their cellulolytic potential. Int J Microbiol. 2012:578925.

35. Shareef I, Satheesh M, Christopher SX. Isolation and Identification of Cellulose Degrading Microbes. Int J Innov Res Sci Eng Technol. 2015;8(4): 6788-93.

36. Troedsson C, Simonelli P, Nägele V, Nejstgaard JC, Frischer ME. Quantification of copepod gut content by differential length amplification quantitative PCR (dla-qPCR). Mar Biol. 2009;156(3):253-9.

37. Woo HL, Ballor NR, Hazen TC, Fortney JL, Simmons B, Davenport KW, et al. Complete genome sequence of the lignin-degrading bacterium Klebsiella sp. strain BRL6-2. Stand Genomic Sci. 2014;9(1):1-9.

38. Quail MA, Smith M, Coupland P, Otto TD, Harris SR, Connor TR, et al. A tale of three next generation sequencing platforms: comparison of lon Torrent, Pacific Biosciences and Illumina Miseq sequencers. BMC Genomics. 2012; 13(1):341.

39. Qiu J, Yang Y, Zhang J, Wang H, Ma Y, He J, et al. The complete genome sequence of the nicotine-degrading bacterium Shinella sp. HZN7. Front Microbiol. 2016;7:1348.

40. Krumsiek J, Arnold R, Rattei T. Gepard: a rapid and sensitive tool for creating dotplots on genome scale. Bioinformatics. 2007;23(8):1026-8.

41. Sommer DD, Delcher AL, Salzberg SL, Pop M. Minimus: a fast, lightweight genome assembler. BMC Bioinformatics. 2007:8(1):64.

42. Solovyev W, Salamov A, Seledtsov I, Vorobyev D, Bachinsky A. Automatic Annotation of Bacterial Community Sequences and Application To Infections Diagnostic. In: Proceedings of the International Conference on Bioinformatics Models, Methods and Algorithms. 2011. p. 346-53.

43. Cantarel BL, Coutinho PM, Rancurel C, Bernard T, Lombard V, Henrissat B. The Carbohydrate-Active EnZymes database (CAZy): an expert resource for glycogenomics. Nucleic Acids Res. 2008;37(suppl_1):D233-8.

44. Park BH, Karpinets T V., Syed MH, Leuze MR, Uberbacher EC. CAZymes Analysis Toolkit (cat): Web service for searching and analyzing carbohydrateactive enzymes in a newly sequenced organism using CAZy database. Glycobiology. 2010;20(12):1574-84.

45. Punta M, Coggill PC, Eberhardt RY, Mistry J, Tate J, Boursnell C, et al. The Pfam protein families database. Nucleic Acids Res. 2012;40(D1):290-301.

46. Jeong DW, Lee $B$, Lee $H$, Jeong $K$, Jang $M$, Lee JH. Urease characteristics and phylogenetic status of Bacillus paralicheniformis. J Microbiol Biotechnol. 2018;28(12):1992-8.

47. Bóka B, Manczinger L, Kocsubé S, Shine K, Alharbi NS, Khaled JM, et al. Genome analysis of a Bacillus subtilis strain reveals genetic mutations determining biocontrol properties. World J Microbiol Biotechnol. 2019;35(3): $1-14$.

48. Bartoszewicz M, Marjańska PS. Milk-originated Bacillus cereus sensu lato strains harbouring Bacillus anthracis-like plasmids are genetically and phenotypically diverse. Food Microbiol. 2017;67:23-30.

49. Tsimpidis M, Bachoumis G, Mimouli K, Kyriakopoulou Z, Robertson DL, Markoulatos P, et al. T-RECs: Rapid and large-scale detection of recombination events among different evolutionary lineages of viral genomes. BMC Bioinformatics. 2017;18(1):1-8.

50. Katoh K, Standley DM. MAFFT multiple sequence alignment software version 7: improvements in performance and usability. Mol Biol Evol. 2013; 30(4):772-80.
51. Kumar S, Stecher G, Tamura K. MEGA7: Molecular Evolutionary Genetics Analysis Version 7.0 for Bigger Datasets. Mol Biol Evol. 2016;33(7):1870-4.

52. Akamatsu R, Suzuki M, Okinaka K, Sasahara T, Yamane K, Suzuki S, et al. Novel Sequence Type in Bacillus cereus Strains Associated with Nosocomial Infections and Bacteremia, Japan. Emerg Infect Dis. 2019;25(5):883-90.

53. Mizrachi E, Hefer CA, Ranik M, Joubert F, Myburg AA. De novo assembled expressed gene catalog of a fast-growing Eucalyptus tree produced by Illumina mRNA-SEq. BMC Genomics. 2010;11(1).

54. Langmead B, Salzberg SL. Fast gapped-read alignment with Bowtie 2. Nat Methods. 2012;9(4):357.

55. Wagner GP, Kin K, Lynch VJ. Measurement of mRNA abundance using RNAseq data: RPKM measure is inconsistent among samples. Theory Biosci. 2012;131(4):281-5.

\section{Publisher's Note}

Springer Nature remains neutral with regard to jurisdictional claims in published maps and institutional affiliations.
Ready to submit your research? Choose BMC and benefit from:

- fast, convenient online submission

- thorough peer review by experienced researchers in your field

- rapid publication on acceptance

- support for research data, including large and complex data types

- gold Open Access which fosters wider collaboration and increased citations

- maximum visibility for your research: over $100 \mathrm{M}$ website views per year

At BMC, research is always in progress.

Learn more biomedcentral.com/submissions 